\title{
Application of Ultrasound-assisted Emulsification Microextraction followed by Gas Chromatography for Determination of Oxadiazon in Water and Soil Samples
}

\author{
Abolfazl Semnani $i^{\mathrm{a}, \mathrm{b}}$, Hedayat Haddadi ${ }^{\mathrm{a}}$, Mohammad Rezaee ${ }^{\mathrm{c}, \boldsymbol{}}$ and Faezeh Khalilian ${ }^{\mathrm{d}}$ \\ ${ }^{a}$ Department of Chemistry, Faculty of Sciences, Shahrekord University P.O. Box 115, Shahrekord, Iran. \\ ${ }^{b}$ Center of Excellence for Mathematics, Shahrekord University P.O. Box 115, Shahrekord, Iran. \\ ${ }^{c}$ Nuclear Fuel Cycle Research School, Nuclear Science \& Technology Research Institute, Atomic Energy Organization of Iran, \\ P.O. Box 14395-836, Tehran, Iran. \\ ${ }^{d}$ Department of Chemistry, College of Basic Science, Yadegar -e-Imam Khomeini (RAH) Branch, Islamic Azad University, Tehran, Iran.
}

Received 27 January 2015, revised 28 April 2015, accepted 29 April 2015.

\begin{abstract}
In this study, a simple and efficient ultrasound-assisted emulsification microextraction (USAEME) method combined with gas chromatography (GC) was developed for the preconcentration and determination of oxadiazon in water and soil samples. In this method, fine droplets of toluene were formed and dispersed in the sample with the help of ultrasonic waves which accelerated the formation of a fine cloudy solution without using disperser solvents. Several factors influencing the extraction efficiency, such as the nature and volume of organic solvent, extraction temperature, ionic strength and centrifugation time, were investigated and optimized. Using optimum extraction conditions a detection limit of $0.1 \mu \mathrm{g} \mathrm{L}^{-1}$ and a good linearity in a calibration range of $0.25-250 \mu \mathrm{g} \mathrm{L}^{-1}$ were achieved for the analyte in a river water sample. This proposed method was successfully applied to the analysis of oxadiazon in water and soil samples.
\end{abstract}

KEYWORDS

Utrasound-assisted emulsification microextraction, oxadiazon, gas chromatography, water samples, soil samples.

\section{Introduction}

Oxadiazon, 5-tert-butyl-3-(2,4-dichloro-5-isopropoxyphenyl)-1,3,4-oxadiazol-2(3H)-one, is an effective herbicide for control of obnoxious grasses and broad-leaf weeds in a wide variety of crops, e.g. citrus fruit, vines, cotton, rice, soya beans and onions. ${ }^{1}$ The chemical structure of oxadiazon is shown in Fig. 1.<smiles>CC(C)Oc1cc(-n2nc(C(C)(C)C)oc2=O)c(Cl)cc1Cl</smiles>

Figure 1 Chemical structure of oxadiazon.

Oxadiazon has been used since the 1970s. Many mono and multi residue chromatographic methods for oxadiazon are available in the litreature..$^{2-5}$ Several methods for the determination of trace amounts of pesticides require the concentration of large volumes of sample by liquid-liquid extraction (LLE) or solidphase extraction (SPE). Solid-phase microextraction (SPME) is an alternative technique that involves direct extraction of the analytes with the use of a small diameter, optical fibre coated with a polymeric stationary phase and housed in a syringe assembly for protection. ${ }^{6-7}$

SPME eliminates the separate concentration step from the SPE and LLE methods, and analytes diffuse directly into the coating of the SPME fibre and are concentrated there. This fibre is then transferred directly into the injection port of the GC where all

*To whom correspondence should be addressed. E-mail:chem.rezaee219@ gmail.com analytes are thermally desorbed and deposited at the head of the GC column. ${ }^{6}$ LLE needs large amounts of toxic solvent and time-consuming procedures. SPE is less time-consuming than LLE but still needs column conditioning and elution with organic solvents; another drawback of SPE is cost. SPME has been applied for determination of oxadiazon. ${ }^{8}$ However, SPME also has some problems such as high cost, sample carry-over and a decline in performance with time.

A more recent technique, introduced by Rezaee et al., which does not involve the use of either a fibre or a syringe has been termed dispersive liquid-liquid microextraction (DLLME). ${ }^{9}$ As the name suggests, it is based on a ternary component solvent system similar to homogeneous liquid-liquid extraction and cloud point extraction. ${ }^{10,11}$ In DLLME a cloudy solution is formed when an appropriate mixture of extraction solvent and disperser solvent is quickly injected into the sample. Thus a high turbulence is produced. This turbulent regimen gives rise to the formation of small droplets, which are dispersed throughout the aqueous sample. Emulsified droplets have a large interfacial area. Only water-immiscible extraction solvents with higher density than water are used, which facilitates their collection as they settle below the aqueous phase after centrifugation. Organic solvents (such as carbon tetrachloride, chloroform or chlorobenzene) are generally used as the extractants in DLLME and are toxic. ${ }^{12-18}$

Ultrasound-assisted emulsification microextraction (USAEME) ${ }^{19}$ is based on the application of ultrasonic radiation for accelerating the emulsification phenomenon. On application of ultrasonic radiation the solution becomes turbid due to the dispersion of extraction droplets into the aqueous phase. The emulsification process favours the mass transfer of analytes from aqueous 
phase into the organic phase which leads to enhanced extraction efficiency of analytes in a minimum amount of time, thereby combining the benefits of microextraction and ultrasonic radiation. USAEME is a fast and efficient microextraction technique for extractions of trace analytes from liquid media. ${ }^{20}$ For the first time, Saleh et al. applied a low-density organic solvent in USAEME. $^{21}$

To the best of our knowledge, none of the published papers reports the use of USAEME for the extraction and determination of oxadiazon in water and soil samples. The aim of this study was the application of the USAEME technique combined with GC-FID for the extraction and determination of oxadiazon in water and soil samples. A series of parameters influencing the extraction recovery were investigated.

\section{Experimental}

\subsection{Chemicals and Reagents}

All reagents were of analytical-reagent grade unless stated otherwise. Oxadiazon and sodium chloride of the highest purity available from Merck (Darmstadt, Germany) were used in this study. A stock standard solution of oxadiazon $(99.5 \%)$ $\left(1000 \mathrm{mg} \mathrm{L}^{-1}\right)$ was prepared in methanol. A fresh $10 \mathrm{mg} \mathrm{L}^{-1}$ standard solution containing the analyte was prepared in methanol every week and stored at $4{ }^{\circ} \mathrm{C}$. The working standard solutions were prepared in doubly distilled water, stored at $4^{\circ} \mathrm{C}$ in a fridge, and brought to ambient temperature prior to use. Toluene, 1-octanol, 1-undecanol, 1-dodecanol were obtained from Merck. The water used was purified on an Aqua Max-Ultra Youngling ultra pure water purification system (370 series, Dongan-gu, Korea).

\subsection{Instrumentation}

A $40 \mathrm{kHz}$ and $0.138 \mathrm{~kW}$ ultrasonic water bath with temperature control (Tecno-Gaz SpA, Strada Cavalli, Parma, Italy) was applied to emulsify the organic solvent. 100 and $25 \mu$ L Hamilton syringes (Bonaduz, GR, Switzerland) were used to inject the organic solvent into samples. Home-designed centrifuge glass vials were used for the extraction and collection procedure (Fig. 2). Separation and quantification of oxadiazon were carried out using an Agilent 7890 gas chromatograph, equipped with a FID detector and a DB-5 fused-silica capillary column ( $30 \mathrm{~m} \times$ $0.32 \mathrm{~mm}$ i.d. $\times 0.25 \mu \mathrm{m}$ film thickness). The injection was per-

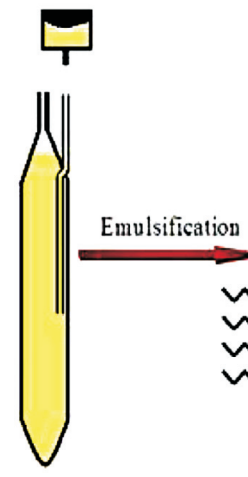

(a)

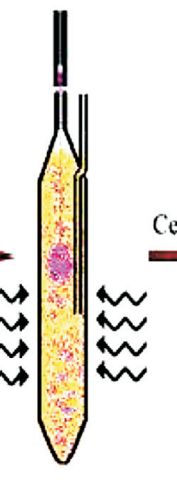

(b)

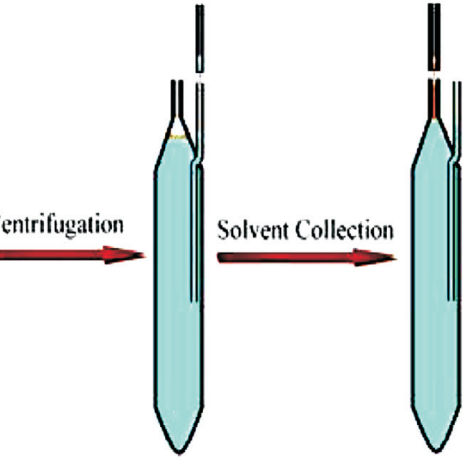

(c) (d)
Figure 2 Schematic representation of the proposed method (a) sample solution in the home-designed emulsification glass vial without salt addition, (b) simultaneous injection and dispersion of $14.0 \mu \mathrm{L}$ toluene into the sample, (c) addition of a few $\mu \mathrm{L}$ of doubly distilled water into the vial and (d) collection of toluene transferred into the capillary tube at the top of the vial (about $6 \mu \mathrm{L})$. formed in splitless mode, and helium gas with high purity was used as carrier at a constant flow rate of $1.5 \mathrm{~mL} \mathrm{~min}^{-1}$. The injector and detector temperatures were 250 and $280{ }^{\circ} \mathrm{C}$, respectively. The column temperature programme was as follows: $75^{\circ} \mathrm{C}$ for $3 \mathrm{~min}$, increased to $270^{\circ} \mathrm{C}$ at $10^{\circ} \mathrm{C} \mathrm{min}-1$, and then held for $1 \mathrm{~min}$, The analytical signal was taken as the peak area of the analyte. A model 2010 D centurion scientific centrifuge (Chichester,West Sussex, United Kingdom) was used for the separation of the floated phase from the sample solution.

\subsection{Ultrasound-assisted Emulsification Microextraction Procedure}

Ten $\mathrm{mL}$ of sample was placed in a home-designed centrifuge glass vial (Fig. 1 a). $14.0 \mu \mathrm{L}$ toluene was injected into the solution and the sample was sonicated for thirty second at $25^{\circ} \mathrm{C}$ in the ultrasonic bath (Fig. 1b). As a result, oil-in-water emulsions of toluene in water were formed. After centrifuging at $3500 \mathrm{rpm}$ for $5 \mathrm{~min}$, the organic solvent droplet separated on the surface of the aqueous solution due to its lower density. A few microlitres of doubly distilled water were added to the vial through the glass tube fixed on the side of the vial (Fig. 1c). The organic solvent rose up the capillary tube attached to the top of the vial and could be collected in a gas-tight syringe (Fig. 1d). The final extract phase was injected into the GC-FID instrument.

\section{Results and Discussion}

In the present study, an ultrasound-assisted emulsification microextraction (USAEME) method was investigated for the preconcentration and determination of oxadiazon in the water and soil samples. The influences of the various parameters such as the kind and the volume of the extraction solvent, ionic strength, extraction temperature and centrifugation time on the extraction efficiency were studied and then the optimum conditions were selected. The optimization of the above mentioned variables was performed using one at a time variable method. All experiments were replicated three times.

\subsection{Selection of Extraction Solvent}

The selection of a suitable extraction solvent is critical for the USAEME process. In USAEME, the extraction solvent should have the following characteristics: ${ }^{21} 1$ ) lower density than that of water, 2) low solubility in water, 3) the ability to extract analytes of interest. Based on these requirements, four organic solvent candidates, toluene, 1-undecanol, 1-dodecanol and 1-octanol were investigated. The results (Fig. 3) revealed that the extraction recovery obtained for the analyte using toluene was higher than recoveries obtained with the other solvents. Therefore, toluene was selected as the extraction solvent for the study.

\subsection{Influence of Centrifugation Time}

Centrifugation is essential to separate extraction solvent from aqueous solution in USAEME. Centrifugation time may affect the volume of the organic phase. The effect of the centrifugation time on the extraction efficiency was examined from 2 to $20 \mathrm{~min}$ at $3500 \mathrm{rpm}$. The experimental results showed that the best performance was obtained at $3500 \mathrm{rpm}$ for $10 \mathrm{~min}$, At higher centrifugation times, the volume of collected solvent decreased.

\subsection{Influence of the Volume of the Extracting Solvent}

The effect of the volume of the extracting solvent on amount of analyte extracted was investigated in the range of $12.0-50.0 \mu \mathrm{L}$. As shown in Fig. 4, increasing the volume of toluene, decreases the preconcentration factor, because the volume of collected solvent increases. Hence, highest preconcentration factors are 


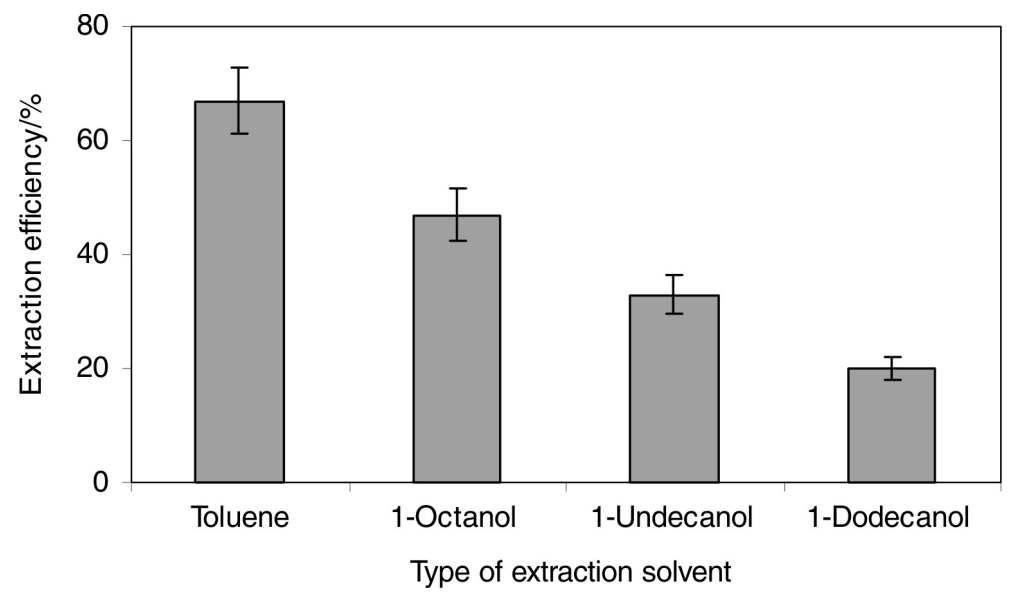

Figure 3 Effect of type of the extraction solvent on the extraction recovery of the analyte. Extraction conditions: sample volume, $10 \mathrm{~mL}$ of $100 \mu \mathrm{g} \mathrm{L}{ }^{-1}$ of the analyte without salt; extraction solvent volumes, $14.0 \mu \mathrm{L}$ toluene, $20.0 \mu \mathrm{L}$ 1-octanol, $12.0 \mu \mathrm{L}$ 1-dodecanol, $10.0 \mu \mathrm{L} 1$-undecanol; concentration of analyte, $100 \mu \mathrm{g} \mathrm{L}^{-1}$; . solution temperature: $25 \pm 3^{\circ} \mathrm{C}$; dispersion time: 30 seconds; centrifugation time: $10 \min (n=3)$

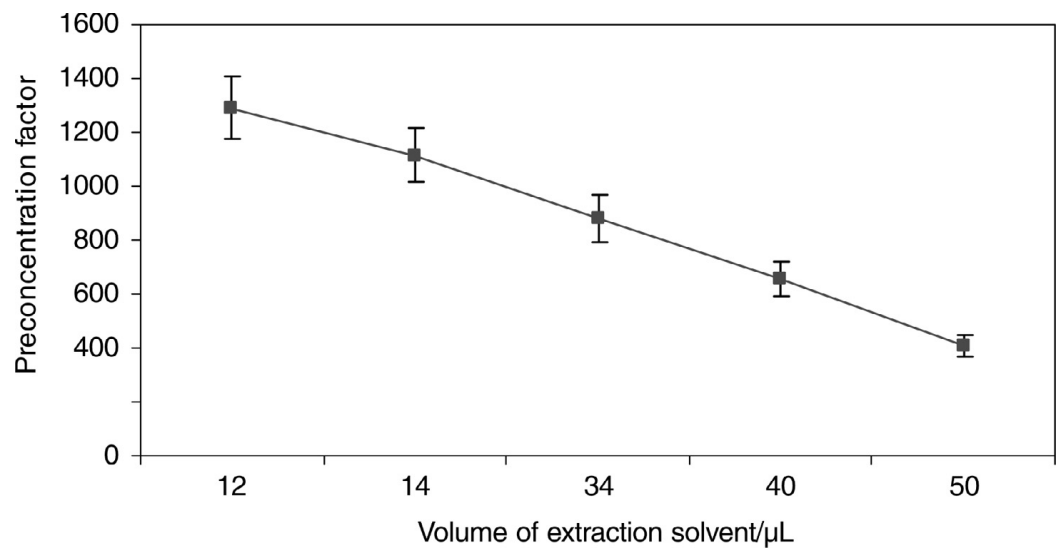

Figure 4 Effect of the extraction solvent volume on the preconcentration factor. Conditions: sample solution: $10 \mathrm{~mL} \mathrm{of} 100 \mu \mathrm{g} \mathrm{L}^{-1}$ of the analyte without salt; volume of toluene: $12.0,14.0,34.0,40.0$ and $50.0 \mu \mathrm{L}$; solution temperature: $25 \pm 3^{\circ} \mathrm{C}$; dispersion time: 30 seconds; centrifugation time: 10 min $(n=3)$.

obtained using $12.0 \mu \mathrm{L}$ volume of extraction solvent. However, problems with the collection of $2 \mu \mathrm{L}$ of toluene meant that better precision was observed when $14.0 \mu \mathrm{L}$ was used. Consequently, $14.0 \mu \mathrm{L}$ was selected as the optimum volume of toluene.

\subsection{Influence of Ionic Strength}

The salting out effect has been universally used in SPME and LLE methods. ${ }^{7,9}$ The addition of salt to an analytical sample can potentially increase the analyte extraction recovery in microextraction procedures. The effect of the ionic strength on the extraction efficiency was evaluated by increasing $\mathrm{NaCl}$ concentrations in the range of $0-8 \%(\mathrm{w} / \mathrm{v})$ in the samples containing $100 \mu \mathrm{g} \mathrm{L}{ }^{-1}$ of oxadiazon. The results show that increasing the concentration of $\mathrm{NaCl}$, does not change the extraction efficiency of oxadiazon significantly. This is possibly because of two opposing effects of salt addition. One is to increase the volume of organic phase and decrease the dispersion efficiency, which reduces the extraction efficiency; the other is the salting-out effect, which increases the extraction efficiency. By increasing the salt concentration, the volume of organic phase increases, because of the decrease of solubility of the extraction solvent in the presence of salt. Therefore, further extractions were performed without addition of salt.

\subsection{Influence of Extraction Temperature}

Temperature affects organic solvent solubility in water as well as the emulsification phenomenon. Consequently, this affects the mass-transfer process and the extraction efficiency. To deter- mine the influence of the extraction temperature, extraction producers were performed at different temperatures such as 20 , 25, 35, 40 and $50{ }^{\circ} \mathrm{C}$. The results are shown in Fig. 5. It was observed that the highest extraction efficiency was obtained in the range $20-25^{\circ} \mathrm{C}$, but at higher temperature $\left(35-50{ }^{\circ} \mathrm{C}\right)$, extraction recoveries decrease. This is possibly because of the decrease in distribution coefficient $\left(\mathrm{K}_{\mathrm{D}}\right)$ at higher temperature. Hence, $25^{\circ} \mathrm{C}$ was used for further experiments.

\subsection{Influence of Extraction Time and Ultrasound Time}

The effect of extraction time on the extraction efficiency was examined in the range $0-40 \mathrm{~min}$, The results show that extraction time has no significant effect on the extraction efficiency of oxadiazon. This showed that the contact surface area between extraction solvent and the sample solution was large and the equilibrium state was achieved quickly. The effect of ultrasound time on the extraction efficiency of oxadiazon was examined in the range 15-180 seconds. The results are shown in Fig. 6. At less than $30 \mathrm{~s}$, extraction efficiency is low, because the ultrasound time is not sufficient for dispersion phenomenon, and the surface area between extraction solvent and sample solution is lower. After $30 \mathrm{~s}$ the extraction efficiency does not change significantly, as an equilibrium state has been achieved. Therefore, $30 \mathrm{~s}$ was selected as the optimum value of ultrasound time for further experiments.

\subsection{Quantitative Analysis}

The characteristics of the calibration curve are shown in Table 1 


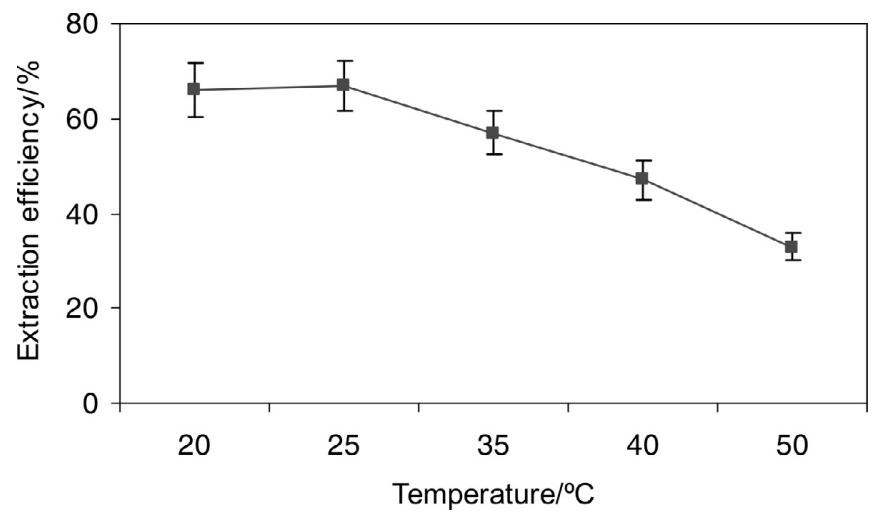

Figure 5 Effect of extraction temperature on the extraction efficiency. Conditions: sample solution: $10 \mathrm{~mL}$ of $100 \mu \mathrm{g} \mathrm{L} \mathrm{L}^{-1}$ of the analyte without salt; volume of toluene: $14.0 \mu \mathrm{L}$; solution temperature: $25 \pm 3^{\circ} \mathrm{C}$; dispersion time: 30 seconds; centrifugation time: 10 min $(n=3)$.

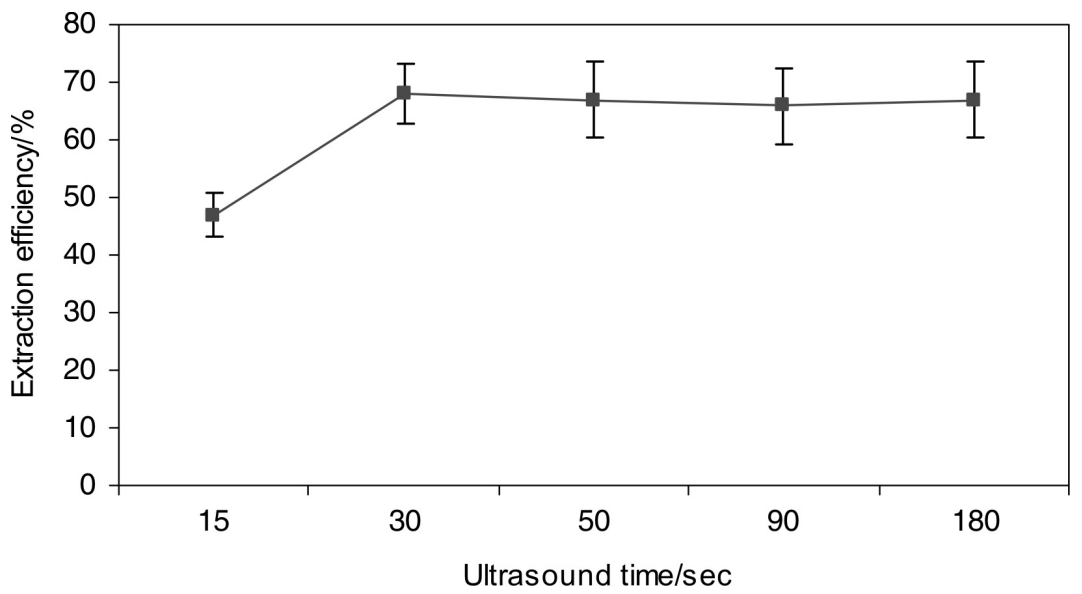

Figure 6 Effect of ultrasound time on the extraction efficiency. Conditions: sample solution: $10 \mathrm{~mL}$ of $100 \mu \mathrm{g} \mathrm{L}^{-1}$ of the analyte without salt; volume of toluene: $14.0 \mu \mathrm{L}$; solution temperature: $25 \pm 3^{\circ} \mathrm{C}$; dispersion time: $15,30,50,90$ and 180 seconds; centrifugation time: $10 \min (n=3)$.

which was obtained under the optimized conditions. Linearity was observed in the range of $0.25-250 \mu \mathrm{g} \mathrm{L}^{-1}$ for oxadiazon with correlation coefficient $\left(r^{2}\right)$ of 0.9992 in river water. The relative standard deviation (RSD) was $7.1 \%(n=8)$ in river water at the concentration level of $5.0 \mu \mathrm{g} \mathrm{L}^{-1}$. The limit of detection (LOD), based on signal-to-noise $(\mathrm{S} / \mathrm{N})$ of three was $0.1 \mu \mathrm{g} \mathrm{L}^{-1}$ in the river water.

Table 2 compares the proposed method with other extraction methods for the determination of oxadiazon. The comparison of extraction time for the proposed method with that for headspace solid-phase microextraction (SPME) ${ }^{22}$ and solid-phase microextraction $^{23}$ indicates that this novel method has a very short equilibrium time compared to the mentioned methods and the extraction time needed for the proposed method is only a few seconds. Quantitative results for the proposed method are better than for headspace solid-phase microextraction ${ }^{22}$ and solidphase microextraction. ${ }^{23}$ The comparison of the proposed method with the electroanalytical determination of oxadiazon ${ }^{24}$

Table 1 Quantitative results of USAEME and GC-FID method for determination oxadiazon.

\begin{tabular}{lcccc}
\hline Sample & $\begin{array}{c}\mathrm{LOD}^{\mathrm{a}} \\
/ \mu \mathrm{g} \mathrm{L}^{-1}\end{array}$ & $\begin{array}{c}\mathrm{RSD}^{\mathrm{b}} \\
/ \%\end{array}$ & $\begin{array}{c}\text { Linear range } \\
/ \mu \mathrm{g} \mathrm{L}^{-1}\end{array}$ & $r^{2 \mathrm{c}}$ \\
\hline River water & 0.1 & 7.1 & $0.25-250$ & 0.9992 \\
Flat water & 0.1 & 6.2 & $0.5-250$ & 0.9991 \\
Sea water & 0.1 & 8.3 & $0.5-250$ & 0.9989 \\
\hline
\end{tabular}

${ }^{\text {a }} \mathrm{LOD}$, limit of detection for $\mathrm{S} / n=3$.

${ }^{\mathrm{b}} \mathrm{RSD}$, relative standard deviation $(n=8)$ at the concentration of $5.0 \mu \mathrm{g} \mathrm{L}{ }^{-1}$.

${ }^{\mathrm{c}}$ Coefficient of determination. indicates that the quantitative results for the proposed method are better, and the proposed method is simple and inexpensive by comparison. Direct comparison of the proposed method with a method not using the ultrasound procedure in the range $20-500 \mu \mathrm{g} \mathrm{dm}^{-3}$ shows that with the ultrasound procedure the preconcentration factor increases, because of the large surface area between extraction solvent and analyte. Also, the comparison of the proposed method with DLLME indicates that consumption of disperser solvent in DLLME leads to disadvantages such as decreasing the partition coefficients of the analyte into the extracting solvent, and increasing the cost as well as environmental pollution, moreover the variety of solvents that can be used with DLLME is limited.

\subsection{Extraction of Oxadiazon from Water Samples}

During the present investigation, matrix effects on the extraction performance were also evaluated by investigating the applicability of the proposed method to determine oxadiazon concentration in river, flat and sea water samples. Physicochemical characteristics are as follow: river water (T: $23.1{ }^{\circ} \mathrm{C}$; $\mathrm{pH}$ : 6.4; EC: $652 \mu \mathrm{s} \mathrm{cm}^{-1}$ and TDS: 410 ); flat water (T: $23^{\circ} \mathrm{C} ; \mathrm{pH}$ : 7.3 and EC: $11.5 \mathrm{ds} \mathrm{m}^{-1}$ ) and sea water (T: $25^{\circ} \mathrm{C}$; $\mathrm{pH}: 7$ and EC: $23 \mathrm{ds} \mathrm{m}^{-1}$ ). These samples were extracted using the USAEME method and analyzed by GC-FID. The results from river, flat and sea water samples showed that they were free of oxadiazon contamination. These samples were spiked with an oxadiazon standard to assess matrix effects. Figure 7 shows the chromatograms obtained for river water and spiked river water.

Relative recoveries were between 90 to $94 \%$. These results (Table 3) demonstrate that the flat, sea and river water matrices, 
Table 2 Comparison of the proposed method with the other extraction methods for determination of the oxadiazon.

\begin{tabular}{|c|c|c|c|c|c|}
\hline Methods & $\%$ RSD & $\begin{array}{l}\text { Dynamic linear range } \\
/ \mu \mathrm{g} \mathrm{L}^{-1}\end{array}$ & $\begin{array}{l}\text { Limit of detection } \\
\qquad / \mu \mathrm{g} \mathrm{L}^{-1}\end{array}$ & $\begin{array}{l}\text { Extraction time } \\
\qquad / \mathrm{min}\end{array}$ & Ref. \\
\hline $\begin{array}{l}\text { Headspace solid-phase } \\
\text { microextraction-GC-MS }\end{array}$ & 7.9 & $0.5-50$ & 0.01 & 2 & {$[22]$} \\
\hline $\begin{array}{l}\text { Solid-phase microextraction- } \\
\text { GC-MS-SIM }\end{array}$ & 8.7 & $0.5-250$ & 0.02 & 30 & [23] \\
\hline $\begin{array}{l}\text { Electroanalytical-cyclic and } \\
\text { square wave voltametry }\end{array}$ & 10.5 & $\begin{array}{l}1.310^{-4} \mathrm{e} \\
2.710^{-4} \mathrm{M}\end{array}$ & $0.0001(\mathrm{M})$ & - & [24] \\
\hline USAEME-GC-FID & 7.1 & $0.25-250$ & 0.1 & A few seconds & This work \\
\hline
\end{tabular}

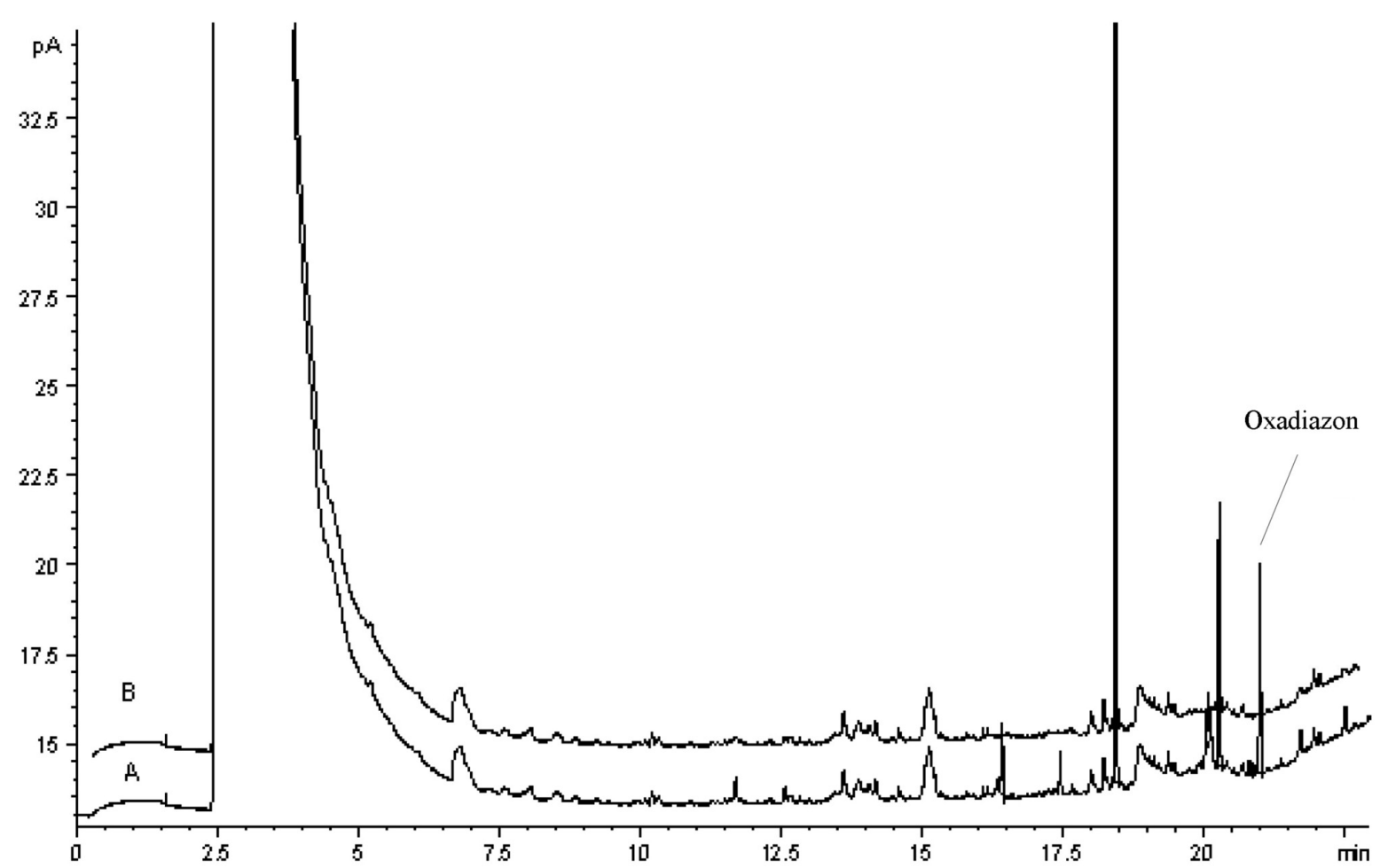

Figure 7 GC-FID chromatograms of the analyte in river water, before spiking (B) and after spiking with $1.0 \mu \mathrm{g} \mathrm{L} \mathrm{L}^{-1}$ of oxadiazon (A) using proposed method combined with GC-FID under optimum conditions.

in our present context, had little effect on the USAEME method. Validation for spiked water samples was carried out by using a one-sample test (Student's $t$-test). ${ }^{25}$ Samples were spiked with different levels of oxadiazon and analyzed by the proposed method. Table 3 shows the results obtained. The P-values calculated in all cases were $>0.05$ and the null hypothesis can be accepted.

\subsection{Extraction of Oxadiazon from Soil Samples}

Soil samples were collected from the north of Iran (Mazandaran, Iran). The physical and chemical properties of soil samples were as follows. Flat soil:silty-clay texture, organic matter: $1.3 \%$, pH: 7.2 and maximum water capacity: $22 \%$. Citrous soil: silty-loam texture, organic matter: $1.57 \%$, pH 7.1 and maximum water capacity: $19.3 \%$. The proposed method combined with

Table 3 Determination of oxadiazon in flat, river and sea water and relative recovery of spiked oxadiazon in them.

\begin{tabular}{|c|c|c|c|c|c|c|}
\hline Sample & $\begin{array}{l}\text { Concentration of } \\
\text { oxadiazon } \\
/ \mu \mathrm{g} \mathrm{L}^{-1}\end{array}$ & $\begin{array}{c}\text { Added concentration } \\
\text { of oxadiazon } \\
/ \mu \mathrm{g} \mathrm{L}^{-1}\end{array}$ & $\begin{array}{c}\text { Determined concentration } \\
\text { of oxadiazon } \\
/ \mu \mathrm{L} \mathrm{L}^{-1} \pm \text { S.D. }, n=3\end{array}$ & $\begin{array}{l}\text { Relative recovery } \\
\qquad / \%\end{array}$ & $t$ & $P$ \\
\hline Flat water ${ }^{a}$ & n.d. ${ }^{d}$ & $\begin{array}{l}5.0 \\
1.0\end{array}$ & $\begin{array}{c}4.6 \pm 0.2 \\
0.90 \pm 0.06\end{array}$ & $\begin{array}{l}92 \\
90\end{array}$ & $\begin{array}{l}1.22 \\
1.76\end{array}$ & $\begin{array}{l}0.36 \\
0.12\end{array}$ \\
\hline River water $^{\mathrm{b}}$ & n.d. & $\begin{array}{l}5.0 \\
1.0\end{array}$ & $\begin{array}{c}4.8 \pm 0.2 \\
0.92 \pm 0.05\end{array}$ & $\begin{array}{l}96 \\
92\end{array}$ & $\begin{array}{l}1.35 \\
1.88\end{array}$ & $\begin{array}{l}0.51 \\
0.22\end{array}$ \\
\hline Sea water ${ }^{c}$ & n.d. & $\begin{array}{l}5.0 \\
1.0\end{array}$ & $\begin{array}{c}4.7 \pm 0.3 \\
0.91 \pm 0.07\end{array}$ & $\begin{array}{l}94 \\
91\end{array}$ & $\begin{array}{l}1.43 \\
1.74\end{array}$ & $\begin{array}{l}0.61 \\
0.26\end{array}$ \\
\hline
\end{tabular}

a From flats in the north of Iran (Sari, Iran).

${ }^{\mathrm{b}}$ From Tejen River (Sari, Iran).

c From Caspian Sea (Rudsar, Iran).

${ }^{\mathrm{d}}$ Not detected. 
Table 4 Determination of oxadiazon in soil samples and relative recovery of spiked oxadiazon in them.

\begin{tabular}{|c|c|c|c|c|c|c|}
\hline Sample & $\begin{array}{l}\text { Concentration of } \\
\text { oxadiazon } \\
/ \mathrm{mg} \mathrm{kg}^{-1}\end{array}$ & $\begin{array}{l}\text { Added concentration of } \\
\text { oxadiazon } \\
/ \mathrm{mg} \mathrm{kg}^{-1}\end{array}$ & $\begin{array}{l}\text { Determined concentration of } \\
\text { oxadiazon } \\
/ \mathrm{mg} \mathrm{kg}^{-1} \pm \text { S.D., } n=3\end{array}$ & $\begin{array}{c}\text { Relative recovery } \\
\qquad / \%\end{array}$ & $t$ & $P$ \\
\hline Flat soil & n.d. ${ }^{a}$ & $\begin{array}{l}0.1 \\
0.05\end{array}$ & $\begin{array}{c}0.09 \pm 0.01 \\
0.044 \pm 0.004\end{array}$ & $\begin{array}{l}90 \\
89\end{array}$ & $\begin{array}{l}2.41 \\
2.55\end{array}$ & $\begin{array}{l}0.08 \\
0.06\end{array}$ \\
\hline Citrous soil & n.d. & $\begin{array}{l}0.1 \\
0.05\end{array}$ & $\begin{array}{c}0.092 \pm 0.01 \\
0.045 \pm 0.004\end{array}$ & $\begin{array}{l}92 \\
90\end{array}$ & $\begin{array}{l}2.33 \\
2.61\end{array}$ & $\begin{array}{l}0.09 \\
0.07\end{array}$ \\
\hline
\end{tabular}

${ }^{\text {a }}$ Not detected.

the ultrasonic assisted extraction was applied to extract oxadiazon from these matrices. Soil samples were pulverized and passed through a $1 \mathrm{~mm}$ sieve. $2.0 \mathrm{~g}$ of the samples accurately weighed and put into a $20 \mathrm{~mL}$ centrifuge tube, to which $3.0 \mathrm{~mL}$ of methanol was added. The resultant samples were ultrasonically extracted for $5 \mathrm{~min}$, After the sonication, the extracts were centrifuged at $5000 \mathrm{rpm}$ for $3 \mathrm{~min}$ and the supernatant liquid was passed through a PTFE syringe filter $(13 \mathrm{~mm}, 0.22 \mu \mathrm{m})$ (SigmaAldrich) to remove particles. For USAEME, a $2.0 \mathrm{~mL}$ aliquot of the residual filtrate and $10.0 \mathrm{~mL}$ of water was placed in a $12 \mathrm{~mL}$ home-designed centrifuge glass vial and ultrapure water was added to fill the tube. Then the sample was submitted to USAEME as described previously.

The recoveries of the analyte from soil samples spiked at 0.1 and $0.05 \mathrm{mg} \mathrm{kg}^{-1}$ levels using the proposed method are given in Table 4 . The relative recoveries for the method for the oxadiazon were in the range $89.0-92 \%$ for the soil samples, indicating good performance of the described method for the determination of the oxadiazon in soil matrices. Validation of the proposed method for soil samples was made using comparison with an ultrasonic extraction method reported by Sanchez-Brunete et al. ${ }^{4}$ as the reference method. Spiked soil samples with concentrations of 0.1 and $0.05 \mathrm{mg} \mathrm{kg}^{-1}$ of oxadiazon were analyzed by both methods. Similar results were obtained with both methods. The statistical comparison of these results by means of a Student's $t$-test showed no significant difference ( $P$-value of $5 \%)$.

\section{Conclusion}

A simple and reliable new ultrasound-assisted emulsification microextraction method was developed for the rapid concentration and determination of oxadiazon in water and soil samples. An ultrasound-assisted process was applied to accelerate the formation of a cloudy solution, which markedly increased the extraction efficiency and reduced the equilibrium time. The developed method was sensitive, reproducible and linear over a wide range. The performance of this procedure in oxadiazon extraction from soil samples was excellent and no matrix effect was observed. Finally, it can be concluded that the broad linear dynamic range combined with the low detection limit suggests a high potential for monitoring oxadiazon in water and soil samples using the USAEME-GC-FID method.

\section{Acknowledgements}

This work has been supported by Shahrekord University through a research fund. The authors were also partially supported by the Center of Excellence for Mathematics, Shahrekord University.

\section{References}

1 C. Tomlin, The Pesticide Manual: a World Compendium, British Crop Protection Council, 11th edn., Farnham, UK, 1997.

2 D.J. George, Chemical contaminants monitoring, Assoc. Off. Anal. Chem., 1982, 65, 1160-1163.
3 A. Tanabe, H. Mitobe, K. Kawata and M. Sakai, Monitoring of herbicides in river water by gas chromatography-mass spectrometry and solid-phase extraction, J. Chromatogr. A, 1996, 754, 159-163.

4 C. Sanchez-Brunete, R. Perez, E. Miguel and J. Tadeo, Multiresidue herbicide analysis in soil samples by means of extraction in small columns and gas chromatography with nitrogen-phosphorus and mass spectrometric detection, J. Chromatogr. A, 1998, 823, 17-24.

5 M.B. Riley and R.J. Keese, Comparison of solid phase extraction techniques for herbicides, Weed Sci., 1996, 44, 689-693.

6 C.L. Arthur and J. Pawliszyn, Solid phase microextraction with thermal desorption using fused silica optical fibres, Anal. Chem., 1990, 62, 2145-2148.

7 C.L. Arthur, L.M. Killam, K.D. Bucholz, J. Pawliszyn and J.R. Berg, Automation and optimization of solid-phase microextraction, Anal. Chem., 1992, 64, 1960-1966.

8 A. Navalon, A. Prieto, L. Araujo and J.L. Vilchez, Determination of oxadiazon residues by headspace solid-phase microextraction and gas chromatography-mass spectrometry, J. Chromatogr. A 2002, 946, 239-245.

9 M. Rezaee, Y. Assadi, M.R. Milani Hosseini, E. Aghaee, F. Ahmadi and S. Berijani, Determination of organic compounds in water using dispersive liquid-liquid microextraction, J. Chromatogr. A, 2006, 1116, $1-9$.

10 S. Oshite, M. Furukawa and S. Igarashi, Homogeneous liquid-liquid extraction method for the selective spectrofluorimetric determination of trace amounts of tryptophan, Analyst, 2001, 126, 703-706.

11 J.L. Manzoori and G. Karim-Nezhad, Development of a cloud point extraction and preconcentration method for $\mathrm{Cd}$ and Ni prior to flame atomic absorption spectrometric determination, Anal. Chim. Acta 2004, 521, 173-177.

12 R. Rahnama Kozani, Y. Assadi, F. Shemirani, M.R. Milani Hosseini and M.R. Jamali, Part-per-trillion determination of chlorobenzenes in water using dispersive liquid-liquid microextraction combined gas chromatography-electron capture detection, Talanta, 2007, 72, 387-393.

13 M.A. Farajzadeh, M. Bahram and J.A. Jonsson, Dispersive liquidliquid microextraction followed by high-performance liquid chromatography-diode array detection as an efficient and sensitive technique for determination of antioxidants, Anal. Chim. Acta, 2007, 591, 69-79.

14 A. Bidari, E. Zeini Jahromi, Y. Assadi and M.R. Milani Hosseini, Monitoring of selenium in water samples using dispersive liquid-liquid microextraction followed by iridium-modified tube graphite furnace atomic absorption spectrometry, Microchem. J., 2007, 87, 6-12.

15 N. Shokoufi, F. Shemirani and Y. Assadi, Fibre optic-linear array detection spectrophotometry in combination with dispersive liquidliquid microextraction for simultaneous preconcentration and determination of palladium and cobalt, Anal. Chim. Acta, 2007, 597, 349-356.

16 M. Rezaee, Y. Yamini, S. Shariati, A. Esrafili and M. Shamsipur, Dispersive liquid-liquid microextraction combined with highperformance liquid chromatography-UV detection as a very simple, rapid and sensitive method for the determination of bisphenol $\mathrm{A}$ in water samples, J. Chromatogr. A, 2009, 1216, 1511-1514.

17 M. Rezaee, Y. Yamini and M. Faraji, Evolution of dispersive liquidliquid microextraction, J. Chromatogr. A, 2010, 1217, 2342-2357.

18 Y. Yamini, M. Rezaee, A. Khanchi, M. Faraji and A. Saleh, Dispersive liquid-liquid microextraction based on the solidification of floating organic drop followed by inductively coupled plasma-optical 
emission spectrometry as a fast technique for the simultaneous determination of heavy metals, J. Chromatogr. A, 2010, 1217, 23582364.

19 M.D. Luque de Castro and F. Priego-Capote, Ultrasound-assisted preparation of liquid samples, Talanta 2007, 72, 321-334.

20. J. Regueiroa, M. Llomparta, C. Garcia-Jaresa, J.C. Garcia-Monteagudob and R. Celaa, Ultrasound-assisted emulsification-microextraction of emergent contaminants and pesticides in environmental waters, J. Chromatogr. A, 2008, 1190, 27-38.

21 A. Saleh, Y. Yamini, M. Faraji, M. Rezaee and M. Ghambarian, Ultrasound-assisted emulsification microextraction method based on applying low density organic solvents followed by gas chromatography analysis for the determination of polycyclic aromatic hydrocarbons in water samples, J. Chromatogr. A, 2009, 1216, 6673-6679.
22 A. Navalon, A. Prieto, L. Araujo and J.L. Vilchez, Determination of tebufenpyrad and oxadiazon by solid-phase microextraction and gas chromatography-mass spectrometry, Chromatographia, 2001, 54, 377-382.

23 A. Navalon, A. Prieto, L. Araujo and J.L. Vilchez, Determination of oxadiazon residues by headspace solid-phase microextraction and gas chromatography-mass spectrometry, J. Chromatogr. A, 2002, 946, 239-245.

24 E.M. Garrido, J.L.F.C. Lima, C. Delerue-Matos, M.F.M. Borges and A.M. Oliveira Brett, Electroanalytical determination of oxadiazon and characterization of its base-catalyzed ring-opening products, Electroanalysis, 2001, 13, 199-203.

25 J.C. Miller and J.N. Miller, Statistics for Chemical Analysis, AddisonWesley Iberoamericana, Wilmington, DE, 1993. 